Virginia Commonwealth University VCU Scholars Compass

2011

\title{
Trends in Alcohol Services Utilization from 1991-1992 to 2001-2002: Ethnic Group Differences in the U.S. Population
}

Karen G. Chartier

University of Texas at Dallas

Raul Caetano

University of Texas at Dallas

Follow this and additional works at: https://scholarscompass.vcu.edu/socialwork_pubs

Part of the Social Work Commons

(C) 2011 by the Research Society on Alcoholism

\section{Downloaded from}

https://scholarscompass.vcu.edu/socialwork_pubs/24

This Article is brought to you for free and open access by the School of Social Work at VCU Scholars Compass. It has been accepted for inclusion in Social Work Publications by an authorized administrator of VCU Scholars Compass. For more information, please contact libcompass@vcu.edu. 


\title{
Trends in Alcohol Services Utilization from 1991-1992 to 2001-2002: Ethnic Group Differences in the U.S. Population
}

\author{
Karen G. Chartier, PhD and Raul Caetano, MD, PhD \\ University of Texas School of Public Health
}

\begin{abstract}
Background-During the early 1990s in the U.S., changes to the provision and financing of alcohol treatment services included reductions in inpatient treatment services and in private sector spending for treatment. We investigated trends in alcohol services utilization over the 10-year period from 1991-1992 to 2001-2002 among U.S. Whites, Blacks and Hispanics.

Method-Data come from two household surveys of the U.S. adult population. The 1991-1992 National Longitudinal Alcohol Epidemiologic Survey (NLAES) and the 2001-2002 National Epidemiologic Survey on Alcohol and Related Conditions (NESARC) conducted face-to-face interviews with a multistage cluster sample of individuals 18 years of age and older in the continental United States. Treatment utilization represented both total utilization and the use of alcohol services. Data analyses were prevalence rates and multivariate logistic regressions for lifetime utilization with drinkers and individuals with alcohol use disorders (AUD).
\end{abstract}

Results-From 1991-1992 to 2001-2002, drinking-related emergency room and human services use increased for drinkers, while total utilization and the use of private health professional services and mutual aid decreased for individuals with AUDs. In drinkers and individuals with AUDs, Blacks and Hispanics were less likely than Whites to use private health professional care. Hispanics with AUDs were less likely than Whites with AUDs to use alcohol or drug programs. Ethnicity interacted with alcohol severity to predict alcohol services utilization. At higher levels of alcohol severity, Blacks and Hispanics were less likely than Whites to ever use treatment and to use alcohol services (i.e., human services for Hispanic drinkers, mental health services for Blacks with AUDs, and mutual aid for Hispanics with AUDs).

Conclusions-Our findings showed increases from 1991-1992 to 2001-2002 in alcohol services utilization for drinkers, but reductions in utilization for individuals with AUDs. Blacks and Hispanics, particularly those at higher levels of alcohol severity, underutilized treatment services compared to Whites. These utilization trends for Blacks and Hispanics may reflect underlying disparities in health care access for minority groups, and language and logistical barriers to utilizing services.

\section{Keywords}

Alcohol Services; Treatment Utilization; Ethnicity; National Trends

\section{INTRODUCTION}

The utilization of alcohol treatment services has historically fluctuated with changes in public policy and the organization and financing of the U.S. healthcare system. During the

Send correspondence to: Karen G. Chartier, PhD, University of Texas School of Public Health, Dallas Regional Campus, 5323 Harry Hines Boulevard, V8.112, Dallas, TX 75390-9128, Phone: 214-648-6574, Fax: 214-648-1081,

Karen.Chartier@UTSouthwestern.edu. 
1980s, private sector alcohol treatment services expanded, significantly increasing the number of people reporting the use of alcohol treatment services (Weisner et al., 1995). This expansion was primarily brought about by the federal government's emphasis on privatization, deregulation and federalism, and new state mandates for minimum insurance coverage for alcohol services (Schmidt and Weisner, 1993; Steenrod et al., 2001). Subsequent concerns about the rising cost of health care initiated a public policy change away from expansion and toward cost containment. In the private insurance sector, cost containment efforts from 1991 to 1996 were primarily accomplished through the establishment of managed care plans (Mark et al., 2005). By the end of the 1990s, more than $60 \%$ of the total U.S. population belonged to a managed health care plan (Galanter et al., 2001), and $78 \%$ of the insurance market for substance abuse and mental health care was controlled by the managed behavioral health care industry (Weisner and Schmidt, 2001).

Efforts to contain health care costs in the 1990s were associated with two major changes in spending for alcohol treatment services, including a sharp decline in spending for inpatient treatment and a reduction in private spending for treatment services. There was a clear shift away from long-term residential services to less expensive, time-limited outpatient services for alcohol treatment (Etheridge et al., 1997; Weisner et al., 1999). Between 1986 and 2003, Mark et al. (2007) noted decreases in spending on inpatient treatment at an average of $1.2 \%$ annually, with the largest reduction from 1992 to 1998 at 6.7\%. Some managed care practices, including requirements for prior approval, limits on days of care, and increased patient cost-sharing (e.g., copayments, coinsurance, and deductibles) for treatment services, are associated with reductions in treatment spending (Gabel et al., 2007; Mark et al., 2005). In particular, a 1999 survey of managed care organizations showed that inpatient treatment, unlike other services, almost always required prior authorization (Magura et al., 2002). Additionally, Mark and colleagues (2005) documented a change from private to public expenditures as the primary funding source for alcohol services in the U.S. They reported 8.3\% annual increase, 1991 to 1996, and 5.4\% annual increase, 1997 to 2001, in public spending for treatment services, along with a respective $2.4 \%$ decrease and $0.1 \%$ increase in private insurance spending. By 2003, state and local government spending accounted for $40 \%$ of total treatment expenditures, followed by Medicaid spending at $18 \%$, and other federal dollars at 15\% (Mark et al., 2007).

The overall reduction during the 1990s in private spending for alcohol treatment services coincided with decreases in alcohol treatment utilization. From 1992 to 2001, based on data from private health insurance plans for large employers, beneficiaries using any alcohol services declined by $23 \%$, including $17.5 \%$ for outpatient services, $53.3 \%$ for inpatient services, and $10 \%$ for pharmaceuticals (Mark and Coffey, 2004). A study using National Drug and Alcoholism Treatment Unit Surveys (NDATUS) data showed decreases in both spending (8\%) and the number of clients (6\%) in specialty treatment services from 1990 to 1994 (Dayhoff et al., 2000). Private and public sector treatment services presented different patterns of spending during this period (i.e., private spending decreased by $28 \%$ and public spending increased by $5 \%$ ), but similar reductions in the number of clients receiving services, $5 \%$ and $6 \%$, respectively. The evidence that managed behavioral health care restricted access to alcohol treatment services has been mixed, showing both increases and decreases in the use of services (Galanter et al., 2001; Steenrod et al., 2001; Weisner et al., 1999). Managed care encompasses a wide range of products (e.g., health maintenance organization (HMOs), preferred provider organizations (PPOs), and point of service (POS) plans), which vary in alcohol treatment coverage and the use of different practices to control utilization, cost, and quality of care (Horgan and Merrick, 2001; Magura et al., 2002).

There is little evidence in the literature for how these changes in the organization and financing of alcohol treatment services have affected rates of treatment utilization for 
Whites, Blacks and Hispanics. U.S. general population studies have primarily examined ethnic group differences in alcohol treatment utilization from a cross-sectional perspective. Schmidt and colleagues (2007) reported no differences in the overall utilization rates of lifetime alcohol services for Whites, Blacks and Hispanics in the general population (total sample: $4.5 \%-5.4 \%$; alcohol use disorder sample: $14.7 \%-16.3 \%$ ) based on the combined 1995 and 2000 National Alcohol Surveys. However, Blacks and Hispanics with higherseverity alcohol problems were less likely to use services compared to Whites. Group differences in the types of services used were also found. Schmidt et al. (2007) showed that Blacks were less likely than Whites to use Alcoholics Anonymous (AA) or to receive help for alcohol problems from a private physician, while Hispanics were less likely than Whites to use a specialty alcohol or drug program.

Data from the 2002 National Survey on Drug Use and Health (NSDUH) suggested a similar need for treatment (i.e., classified by meeting one of three criteria in the past year, including alcohol dependence, alcohol abuse or receiving specialty alcohol treatment) across Whites (8.0\%), Blacks (7.4\%) and Hispanics (8.6\%) (Substance Abuse and Mental Health Services Administration, 2005). Yet fewer Hispanics (5.5\%) needing alcohol treatment received specialty alcohol treatment (i.e., alcohol and drug rehabilitation program, hospital or mental health center) compared to Whites (8.4\%) and Blacks (11.8\%). Blacks are reportedly overrepresented in public alcohol programs (Kaskutas et al., 1999; Weisner and Schmidt, 2001), which may reduce certain barriers to accessing specialty alcohol treatment programs. In particular, Weisner et al. (2002) found that Blacks were more likely than Whites to enter a specialty treatment program regardless of insurance status, while Hispanics with health insurance were less likely than Whites to be in an alcohol treatment program. Despite ethnic group differences, Kaskutas et al. (1997) identified AA or 12-step programs as the most frequently used alcohol treatment service for Whites, Blacks and Hispanics.

The current paper adds to the existing research on temporal changes in alcohol treatment utilization by examining more recent trends in the use of alcohol treatment services, 1991-1992 to 2001-2002, specifically focusing on White, Black and Hispanic ethnic groups. Weisner et al. (1995) found linear increases in treatment utilization from 1979 to 1984 and 1990, including for overall help seeking and the use of AA, alcohol program, general hospital, and health and mental health program services for alcohol problems. Previous studies of treatment utilization, documented above, overlap the 1991-1992 to 2001-2002 study periods, but do not test differences in utilization trends by ethnicity. Absent from these trend studies is also an assessment of participation in 12-steps meetings or mutual aid. This paper examined the utilization of alcohol treatment in a general population sample of Whites, Blacks and Hispanics. We took a broad view of alcohol treatment services to include alcohol or drug programs, mutual aid, and services provided in mental health, medical and human services settings (Weisner and Schmidt, 2001). We used National Longitudinal Alcohol Epidemiologic Survey (NLAES) data from 1991-1992 and National Epidemiologic Survey on Alcohol and Related Conditions (NESARC) data from 2001-2002 to investigate U.S. trends in alcohol services utilization. Changes in overall help seeking or total utilization and the use of alcohol service types were examined across the three ethnic groups.

Based on our review of earlier studies, we expect to find reductions in the use of alcohol treatment services from 1991-1992 to 2001-2002, corresponding with the expansion of cost containment efforts during this time period. We hypothesize that the effect of spending reductions, most profound in the private insurance sector, will be more likely to impact Whites compared to Blacks and Hispanics. Despite the predicted greater declines in treatment use for Whites from 1991-1992 to 2001-2002, we expect that Black and Hispanics will be less likely than Whites to ever use alcohol treatment services, particularly at higher 
levels of alcohol severity. Different rates of utilization are also hypothesized between Whites, Blacks and Hispanics for some types of alcohol treatment services. Relative to Whites, Blacks will be less likely to use help from a private health professional for alcohol problems and Hispanics will be less likely to use an alcohol or drug program. Mutual aid or 12-step meetings are expected to be the most frequently used alcohol treatment service regardless of ethnic group membership.

\section{METHODS}

The National Institute on Alcohol Abuse and Alcoholism (NIAAA) sponsored the 1991-1992 NLAES and the 2001-2002 NESARC (Grant et al., 2004). These surveys were designed to assess the magnitude of alcohol use disorders and their associated disabilities in the general population. The U.S. Bureau of the Census conducted the fieldwork for both surveys using face-to-face interviews and trained interviewers. The overall survey response rate for the NLAES was 90\%; the household response rate $92 \%$ and the person response rate $98 \%$. The response rates for the NESARC were comparable, with an overall response rate of $81 \%$, a sampling frame response rate of $99 \%$, and household and person response rates of $89 \%$ and $93 \%$, respectively. A multistage stratified probability sampling method was utilized to select the NLAES and NESARC samples.

The NLAES was a nationwide household survey involving 42,862 respondents (National Institute on Alcohol Abuse and Alcoholism., 2008). The sample was representative of civilian, non-institutionalized adults, 18 years of age and older, living in the contiguous United States and the District of Columbia. Military personnel living off-base were included in the sample. There was an oversample of Blacks and young adults (ages 18-29 years). The NESARC included 43,093 respondents. The NESARC was a national sample representative of civilian, non-institutionalized adults, aged 18 and older, residing in the United States including all 50 states and the District of Columbia (Grant and Dawson, 2006). Military personnel living off-base and residents in non-institutionalized group quarters housing, such as rooming houses, motels, college quarters, group homes and shelters, were sampled. Black and Hispanic households, in addition to young adults (ages 18-24 years) were oversampled in the survey. We excluded NESARC respondents residing in Alaska and Hawaii from the current study since the states of Alaska and Hawaii were not included in the NLAES sampling plan.

This general population study included White, Black and Hispanic drinkers from the NLAES $(N=26,561)$ and NESARC $(N=26,249)$ and a subsample of respondents with a lifetime Diagnostic and Statistical Manual, fourth edition (DSM-IV) (American Psychiatric Association, 1994) alcohol use disorder (NLAES: $N=7,077$; NESARC: $N=11,358$ ). Respondents who reported drinking 12 or more drinks on a lifetime basis were defined as drinkers. The Alcohol Use Disorder and Associated Disabilities Interview Schedule-DSMIV Version (AUDADIS-IV) was administered for both the NLAES and NESARC. The AUDADIS-IV generated diagnoses for alcohol abuse and dependence, defined as meeting criteria for at least one out of four symptoms for abuse and at least three out of seven symptoms for dependence. The diagnosis of alcohol use disorder included respondents that met lifetime criteria for either abuse or dependence or both. In test-retest studies, the reliability of AUDADIS-IV alcohol abuse and dependence diagnoses were reported to be good to excellent (Grant et al., 1995). The kappa coefficient for past year alcohol abuse and dependence was $0.76( \pm 0.05 \mathrm{SE})$, and $0.73( \pm 0.06)$ for prior to past year abuse and dependence.

Based on the 1991-1992 NLAES, Grant and Dawson (1999) reported a lifetime alcohol use disorder rate of $18.2 \%$ in the U.S. population. Hasin et al. (2007) reported a lifetime alcohol 
use disorder rate of 30.3\% for the U.S. population based on the 2001-2002 NESARC. Among drinkers in this study, a smaller percentage of Blacks (NLAES: 20.86\%; NESARC: $36.82 \%$ ) compared to Whites (NLAES: $28.03 \%$; NESARC: $48.01 \%$ ) and Hispanics (NLAES: $29.24 \%$; NESARC: $37.56 \%$ ) met criteria for a lifetime alcohol use disorder. Changes between the NLAES and NESARC in prevalence rates of lifetime alcohol abuse or dependence have not been formally tested, but the above rates appear to suggest a substantial increase in lifetime alcohol use disorders in the population and across ethnic groups from 1991-1992 to 2001-2002. Some methodological differences in the construction of the alcohol abuse and dependence diagnoses between the surveys may account for the lifetime increases in alcohol use disorders. Grant et al. (2004) noted the addition of some new questions in the NESARC used for determining the abuse and dependence symptoms of hazardous drinking, tolerance, and continued drinking despite recurrent physical or psychological problems, as well as differences in how the two surveys measured the duration of a symptom (i.e., the repetitiveness with which a symptom occurred). These differences in the operationalization of alcohol abuse and dependence were reported to be minor when applied to 12-month diagnoses (Grant et al., 2004), but their impact on lifetime diagnoses requires further investigation.

\section{Measures}

Alcohol Services Utilization-Lifetime measures of alcohol treatment utilization were utilized to allow adequate sample sizes for analyses conducted in Whites, Blacks and Hispanics. In both surveys, drinkers were asked if they ever sought help (yes or no) for reasons related to their drinking. Follow-up questions assessed contact with specific types of professionals, organizations and/or programs for help with alcohol problems. Horgan and Merrick (2001) organized the variety of services that make up the alcohol treatment system into three sectors: 1) specialty programs for alcohol or drug use and mental health disorders, 2) non-specialty medical services (e.g., primary care and emergency rooms), and 3) other sectors (e.g., self-help groups and human services). For this study, we expanded these sectors to include five categories, 1) specialty programs, 2) non-specialty medical services, 3) mutual aid, 4) non-specialty human services and 5) other services. The NLAES and NESARC surveys contain similar questions regarding the use of these alcohol treatment categories, but there are some differences which we have noted below. Specialty programs were defined separately in the study by two variables. 1) Alcohol or drug programs included alcohol detoxification clinics and alcohol or drug rehabilitation programs. 2) Mental health services consisted of those provided by an inpatient psychiatric ward or general hospital, community mental health center, outpatient clinic, or outreach and day or partial patient program. The NLAES asked about the use of these services in four separate questions, while the NESARC combined these services into two questions (i.e., "Ever went to inpatient ward of a psychiatric/general hospital or community mental health program" and "Ever went to outpatient clinic, including outreach and day/partial patient program"). Non-specialty medical services for this study also included two variables, i.e., 1) care by a private health professional and 2) emergency room care. The health professional variable represented help provided by a private physician, psychiatrist, psychologist and social worker, but not a natural therapist (i.e., a profession excluded from the NESARC survey). The NLAES used separate questions to ask about help provided by these four health professionals, while the NESARC had one question asking about help provided by a "private physician, psychiatrist, psychologist, social worker, or any other professional". Both surveys asked about the use of an emergency room (ER) as an alcohol treatment service. Only the NESARC question restated ER utilization "because of drinking". Mutual aid for this study involved participation in 12-step meetings for Alcoholics Anonymous (AA), Narcotics Anonymous (NA) and/or Cocaine Anonymous (CA). The NESARC asked about participation in AA, NA or CA and other 12-step meetings in a single question. The NLAES measured AA, NA and 
CA participation in two questions; one question for AA meetings and a second question for NA or CA meetings. For this study, non-specialty human services was one variable, representing alcohol services provided by a family or social service agency and an employee assistance program. Other service types represented those services with low rates of use in the population, including clergy, halfway house, and crisis center. The NLAES had additional questions about the use of vocational rehabilitation and methadone maintenance programs. Because the NESARC did not include questions about these services for alcohol problems, they were not examined for this study.

Socio-demographic Variables-NLAES and NESARC respondents were asked to provide information about their race/ethnicity, gender, age, level of education, income, marital status, and health insurance coverage. For the purpose of this study, age was categorized into five groups (i.e., 18-29, 30-39, 40-49, 50-59, and 60 years and older). Respondents' highest year of school completed was coded: 1) less than high school, 2) high school or a general equivalency degree (GED), 3) some college or 2-year technical degree, and 4) 4-year college degree or more education. Annual family income had 5 categories, 1) less than $\$ 15,000,2) \$ 15,000$ to less than $\$ 30,000,3) \$ 30,000$ to less than $\$ 50,000,4$ ) $\$ 50,000$ to less than $\$ 75,000$, and 5) $\$ 75,000$ or more. Current marital status consisted of three groups, including 1) married or living with someone as if married (i.e., cohabitating), 2) widowed, divorced or separated, and 3) never married. Health insurance included, 1) private or employee provided coverage, 2) public insurance coverage (i.e., Medicare, Medicaid, or military health care), and 3) no insurance coverage.

Alcohol Severity-We defined alcohol problem severity by the number of alcohol dependence criteria endorsed by a respondent in his/her lifetime (0-7). The alcohol dependence criteria were based on the DSM-IV, and included 1) tolerance, 2) withdrawal from alcohol or drinking to avoid or relieve withdrawal, 3) drinking alcohol in larger amounts or over a longer period of time than intended, 4) desire or unsuccessful attempts to cut down or control alcohol use, 5) great deal of time spent obtaining, using or recovering from drinking alcohol, 6) giving up or reducing important activities for drinking, and 7) continued use of alcohol despite physical or psychological problems (National Institute on Alcohol Abuse and Alcoholism, 1998; 2006). Earlier studies have used alcohol dependence symptoms to show alcohol severity and to predict the utilization of alcohol services (Kaskutas et al., 1997; Schmidt et al., 2007; Weisner et al., 1995).

\section{Data Analysis}

Our analysis of NLAES and NESARC data examined trends in alcohol services utilization for Whites, Blacks and Hispanics in the general population. The statistical package SUDAAN (Research Triangle Institute, 2008) was used for all analyses due to the complex multistage sample designs used by the NLAES and NESARC. Appropriate weight specifications for the datasets were used (F. S. Stinson, personal communication, June 26, 2006). These weights corrected for oversampling, non-response and the probability of selection at the household level, and adjusted survey data to the U.S. Census data.

The proportions or mean statistics for socio-demographic variables and alcohol severity were examined by survey year for drinkers and respondents with a lifetime alcohol use disorder. The $\chi^{2}$ test of independence was used to examine survey year differences on categorical measures, while the independent $t$-test was applied to continuous data. The $\chi^{2}$ test of independence also assessed the prevalence of utilization by survey year, disaggregating data by ethnic group and gender within each ethnic group. Analyses were conducted to examine trends in both ever seeking help for drinking or overall utilization and the lifetime utilization of specific services. Trends in utilization were tested separately 
among drinkers and individuals with an alcohol use disorder (AUD). To adjust for multiple significance testing in bivariate analyses, we used a probability value of $<.01$ in determining statistically significant findings.

Multivariate logistic regression models examined alcohol services utilization (obtaining services vs. not obtaining services) using a merged NLAES and NESARC dataset. These analyses tested survey year (reference: NLAES, 1991-1992) and ethnic group (reference: White) differences in alcohol services use after controlling other socio-demographic characteristics. Gender (reference: female), age (reference: ages 18-29), education (reference: less than high school), income (reference: less than $\$ 15,000 /$ year), marital status (reference: married or cohabitating), health insurance coverage (reference: private or employee), and the continuous variable alcohol severity were covariates in the models.

Five multivariate models were tested for the AUD subsample $(N=18,435)$, predicting ever seeking help and the utilization of the most common alcohol services (i.e., mutual aid, alcohol or drug programs, mental health services, and private health professionals). Three models were tested for the drinkers sample $(N=52,120)$, predicting private health professional, ER, and human services utilization for alcohol problems. Non-specialty medical and human services sectors may represent important alcohol services for drinkers or individuals at risk for alcohol use disorders (Horgan and Merrick, 2001). Multivariate analyses were conducted in two steps. 1) The main effects for survey year (reference: NLAES, 1991-1992), ethnicity (reference: White) and covariates were tested in predicting alcohol services use. 2) The interaction effects for survey year and ethnicity, and ethnicity and alcohol severity were separately entered into study models. These interaction terms assessed survey year differences in alcohol services use across ethnic groups and the effect of alcohol severity as a moderator of the relationship between ethnicity and treatment utilization, respectively.

\section{RESULTS}

\section{Sample Demographic Characteristics by Survey}

For drinkers (See Table 1), most respondents in the sample were White in 1991-1992 and 2001-2002. However, the proportions of White respondents decreased and of Black and Hispanic respondents increased between survey years. The majority of drinkers were male with no change over the 10 years. Drinkers were older in 2001-2002 versus 1991-1992; the percentages of younger respondents (i.e., 18 to 39) decreased and older respondents increased (i.e., 40 to $60+$ years). Similarly, the proportions of drinkers at higher levels of education and income (i.e., some college or more and $\$ 50,000$ or more) increased. Changes in marriage by survey year showed decreased percentages of being married/cohabitating for drinkers. The proportion of drinkers with private insurance coverage decreased, with corresponding increases in public and no insurance coverage. Drinkers' reported level of alcohol problem severity decreased.

In the AUD subsample, there were no significant changes by survey year in ethnic group membership or gender. Most respondents were White and male in both 1991-1992 and 2001-2002. Among individuals with AUDs, the proportions of respondents in older age groups (i.e., 40 to $60+$ years), with more education (i.e., some college or more) and at higher income levels (i.e., $\$ 50,000$ or more) increased over the 10 years. A lower percentage of respondents reported never being married in 2001-2002 versus 1991-1992. Rates of being privately insured decreased, while rates of having public insurance increased and having no coverage showed little change. Alcohol problem severity for individuals with AUDs decreased from 1991-1992 to 2001-2002. 


\section{Trends in Alcohol Services Utilization}

For the drinkers sample, there were no survey year differences (Table 2; 1991-1992 vs. 2001-2002) in the prevalence of overall treatment utilization (i.e., ever sought help) for Whites, Blacks and Hispanics. However, the use of some specific treatment services for White and Black drinkers increased from 1991-1992 to 2001-2002. All Whites and White males showed increased utilization of ER care and human services for alcohol problems, while no changes in utilization were found for White women. We also identified increases in ER care for all Blacks, 'other services' for Black men, and mental health services for Black women. All survey year changes for Hispanic drinkers in the types of service used, including for Hispanic males and females, were non-significant.

Among individuals with an alcohol use disorder (AUD; Table 3), changes in overall treatment seeking were observed for Whites only. The prevalence of ever seeking help for alcohol problems decreased significantly from 1991-1992 to 2001-2002 for all Whites, as well as for White males and females. These decreases ranged from 3.8 to 7.5 percentage points and were larger for White males compared to White females. We also identified significant trends in the use of specific alcohol services, again for Whites but not for Blacks and Hispanics. All Whites showed decreased utilization of alcohol or drug programs, mental health services, private health professionals, and mutual aid. The largest decrease for all Whites was observed for mutual aid. By gender, decreases in the use of alcohol or drug programs, private health professionals, and mutual aid were identified for White males, and in health professional services and mutual aid for White females. Mutual aid (i.e., 12-step meetings) was the most common alcohol service utilized in the AUD subsample, followed by alcohol or drug programs. Other common alcohol services were provided in mental health settings and by a private health professional.

\section{Multivariate Models of Alcohol Services Utilization}

Table 4 presents multivariate logistic regression models for the AUD subsample of Whites, Blacks and Hispanics, assessing predictors of overall treatment utilization and utilization of the top four alcohol services (i.e., mutual aid, alcohol or drug programs, mental health services, and private health professionals). Main effects models are presented for alcohol or drug program utilization and health professional care. Significant interaction effects for ethnicity and alcohol severity were found in models predicting ever seeking help, mental health services and mutual aid; interactive models are presented for these utilization outcomes. Relative to Whites, Hispanics were less likely to use alcohol or drug programs and a health professional for help with alcohol problems, while Blacks were less likely to use health professionals. With increasing alcohol severity, Blacks and Hispanics had lower odds than Whites of ever utilizing alcohol treatment. Additionally, Blacks had lower odds of using mental health services and Hispanics had lower odds of mutual aid utilization compared to Whites at higher levels of severity. The interaction effect between survey year and ethnicity was not statistically significant in any of the alcohol services models tested, showing a constant effect for survey year across ethnic groups. Alcohol treatment utilization varied by survey year for overall treatment and for some alcohol treatment services. Respondents in 2001-2002 were less likely than respondents in 1991-1992 to ever seek help and to use a health professional or mutual aid for alcohol problems.

Covariates tested in models for alcohol services utilization in the AUD subsample included gender, age, education, income, marital status, health insurance coverage, and alcohol severity. Males were more likely to ever use treatment, alcohol or drug programs, mental health services, and 12-step meetings compared to females, while both genders had similar odds of seeing a private health professional. Older age generally indicated a higher likelihood of using alcohol treatment relative to 18-29 year olds. In particular, respondents 
40-49 and 50-59 years of age were more than twice as likely to use alcohol or drug programs and mutual aid. A college education predicted a lower likelihood of total and alcohol or drug program use (compared to < high school), but higher levels of education were associated with increased odds of using alcohol services provided by a health professional. Higher income (compared to $<\$ 15,000$ ) predicted lower odds of alcohol services utilization, although not consistently across all income levels. For example, individuals in all higher income levels showed lower odds of utilization for mental health services, while only those individuals with incomes of $\$ 50,000$ to less than $\$ 75,000$ were less likely to utilize alcohol or drug programs. Respondents who were separated, divorced, widowed or never married had greater odds of service use in all models. Similarly, public health insurance coverage compared to private coverage was associated with a greater likelihood of overall utilization and the use of all service types. Respondents with neither public nor private coverage (versus private coverage) were more likely to ever seek help and to use mutual aid only. Alcohol severity was a strong predictor of treatment use. In models for alcohol or drug programs and private health professional care, respondents were twice as likely to use services with each added alcohol dependence symptom.

Multivariate logistic regression models for drinkers predicting the utilization of nonspecialty alcohol services in medical and human services settings are presented in Table 5 . Health professional services and emergency room care are main effects models, while human services utilization is an interaction model. The effect of ethnicity on humans services use was moderated by alcohol severity. However, the interaction effect between survey year and ethnicity in predicting utilization was non-significant in all models. Relative to 1991-1992, drinkers in 2001-2002 were less likely to receive care provided by a health professional for alcohol problems, but were more likely to use emergency room care and human services. Whites, Blacks and Hispanics had similar odds of using the ER for alcohol problems. Ethnic group differences were found for health professional care, with Blacks and Hispanics being at lower odds of utilization compared to Whites. At increased levels of severity (an ethnicity-alcohol severity interaction effect), Hispanics were less likely than Whites to utilize alcohol services provided in a human services setting.

Being separated, divorced or widowed and having public health insurance coverage consistently predicted a greater likelihood of alcohol services utilization among drinkers. For health professional and ER care, increased alcohol severity predicted more than 2 times the likelihood of utilizing services. Males were more likely to use non-specialty treatment services with the exception of private health professional care, which showed no significant difference between males and females. Older age generally predicted greater treatment utilization, although individuals 60 years or older compared to 18 to 29 year olds were less likely to use alcohol services in a human services setting. Higher levels of education (versus less than high school) predicted a greater likelihood of receiving treatment from a health professional, but showed no relationship to ER care or human services use. Utilization in drinkers varied little by income; only individuals with yearly incomes of $\$ 15,000$ to less than $\$ 30,000$ and $\$ 30,000$ to less than $\$ 75,000$ were less likely (compared to $<\$ 15,000$ ) to use health professional care and ER care, respectively.

\section{DISCUSSION}

The present study documented changes in alcohol services utilization for Whites, Blacks and Hispanics in U.S. general population samples from 1991-1992 and 2001-2002. We identified changes from 1991-1992 to 2001-2002 in the prevalence of treatment utilization for Whites and Blacks, but not for Hispanics in drinkers and individuals with AUDs. Among drinkers, Whites and Blacks had a higher prevalence of using some alcohol treatment services (i.e., ER and human services) in 2001-2002 versus 1991-1992. Conversely, Whites 
with AUDs showed lower rates of overall treatment utilization and the use of alcohol or drug programs, mental health services, health professional care and mutual aid in 2001-2002 compared to 1991-1992.

Multivariate tests confirmed increased rates of ER and human services utilization for drinkers in the U.S. population from 1991-1992 to 2001-2002. These effects of survey year on utilization were constant across ethnic groups. The reasons for these increases in utilization require further investigation. Grant et al. (2004) showed an increase in the prevalence of alcohol abuse between 1991-1992 and 2001-2002, possibly indicating a higher percentage of drinkers consuming alcohol at risky levels and requiring care related to drinking. Dawson et al. (2004), for the same 10-year period, reported an increase in the proportion of Whites exceeding weekly drinking limits, but a decrease in the proportion exceeding daily drinking limits. Caetano et al. (2010) reported trend analyses in binge drinking between 1991-1992 and 2001-2002 that showed an increase in the proportion of White, Black and Hispanic men reporting binge drinking once a week or more. The increased utilization of the ER and human services could also mean a shift in the types of services being used by individuals. For example, because ERs in the U.S. provide care for all individuals independent of their health insurance status and ability to pay, if the proportion of uninsured or underinsured in the population goes up, ER visits can also go up (Institute of Medicine, 2003; Institute of Medicine, 2007). While these explanations are plausible, they may not provide a full account for the increased rates of utilization reported by drinkers and other explanations not considered here are likely.

The decreased prevalence rates of treatment utilization for individuals with AUDs between survey years, 1991-1992 to 2001-2002, diverged from earlier trend studies on treatment utilization. Weisner et al. (1995) reported substantial increases in treatment utilization from 1979 through 1990. Huber et al. (1994) reported a doubling of national spending on specialty alcohol treatment, $1979-1989$, from $\$ 1.6$ billion to $\$ 3.8$ billion in 1989 dollars. For this study, in multivariate analyses, the odds of ever seeking treatment and of using alcohol services from a health professional and mutual aid were lower in 2001-2002 compared to 1991-1992 in the AUD subsample.

These reductions in alcohol services use for individuals with AUDs may be linked to changes during the 1990s in spending and organization of alcohol treatment services. There was a shift away from spending on inpatient to outpatient treatment services and from private to public spending for alcohol treatment (Etheridge et al., 1997; Mark et al., 2005; Mark et al., 2007; Weisner et al., 1999). These changes coincided with sizeable decreases in overall treatment utilization and in the use of different service types for private insurance beneficiaries (Mark and Coffey, 2004). Specialty treatment services showed reductions in utilization for both individuals with public and private insurance coverage (Dayhoff et al., 2000). Since Whites are more likely than other ethnic groups to have private or employment-based health insurance (Copeland, 2005), we expected that they would be more susceptible to these spending changes in treatment services. Only Whites with AUDs showed reduced prevalence rates in bivariate analyses for ever seeking help and for utilizing specific alcohol treatment services. However, the effect of survey year on treatment utilization in multivariate analyses did not vary by ethnicity. Explanations for the decline of mutual aid utilization, a free service, are less clear. However, studies conducted with alcohol treatment samples demonstrate a strong link between formal treatment services and AA meeting participation and practices (Arroyo et al., 1998; Kaskutas et al., 1997; Kaskutas et al., 1999; Tonigan et al., 2002). Declines in formal alcohol treatment services could inadvertently reduce participation in 12-step meetings. 
Blacks and Hispanics were identified in multivariate models as being at risk for the underutilization of alcohol services from 1991-1992 to 2001-2002. We expected that Blacks would be less likely to use private health professional services and Hispanics less likely to use alcohol or drug programs compared to Whites (Schmidt et al., 2007; Substance Abuse and Mental Health Services Administration, 2005; Weisner et al., 2002). These hypotheses were supported. Blacks in this study were less likely than Whites to use health professional care in drinkers and individuals with AUDs. Hispanics were less likely to use alcohol or drug programs in the AUD subsample and to use help from a health professional for alcohol problems in both samples. The lower utilization of health professional services for Blacks and Hispanics may reflect larger disparities trends in access to care for minority groups. For instance, data from the Agency for Healthcare Research and Quality (2000, February) show that more Blacks and Hispanics than Whites (i.e., 20\% and 30\% versus < $16 \%$, respectively) do not have a regular source of health care. Additionally for Hispanics, language and other logistical barriers may limit access to alcohol or drug programs. Zemore et al. (2009) identified greater barriers to treatment utilization for Spanish-speaking (versus Englishspeaking) Hispanics in the general population. Schmidt et al. (2007) reported concerns about paying, finding services, and obtaining child care as barriers for Hispanics in obtaining alcohol treatment. These findings are particularly concerning since Blacks and Hispanics are recognized as high risk groups for alcohol-related problems (Chartier and Caetano, 2010). Mulia et al. (2009) identified Black and Hispanic drinkers as more likely than White drinkers to report alcohol dependence symptoms and social consequences from drinking.

Furthermore, Schmidt et al. (2007) found Hispanics and Blacks with more severe alcohol problems to be less likely than Whites with similar severity to ever use alcohol treatment services. We also showed for the AUD subsample that Blacks and Hispanics had lower odds of ever seeking help than Whites at higher levels of alcohol severity. We found similar interaction effects between ethnicity and severity in predicting the use of human services for Hispanic drinkers, mental health services for Blacks with AUDs, and mutual aid for Hispanics with AUDs. To our knowledge, this is the first study to test the effects of alcohol problem severity on ethnic group differences in treatment utilization for specific alcohol service types. In previous studies, for example, only main ethnic group differences in the use of 12-step meetings were reported (Arroyo et al., 1998; Kaskutas et al., 1999; Schmidt et al., 2007; Tonigan et al., 2002). However, as hypothesized, mutual aid was the most common service used among Whites, Blacks and Hispanics. This identification of 12-step meetings as the customary alcohol treatment service in the U.S. replicates earlier studies (Kaskutas et al., 1997; Owen et al., 2003; Weisner et al., 1995).

This study's findings should be considered in light of several strengths and limitations. The NLAES and NESARC datasets are large, representative national adult samples drawn from the general U.S. population. They provide significant statistical power for the current analyses. Findings generated from the use of these datasets could be generalized to the U.S. population of drinkers and to the subgroup of individuals with alcohol use disorders. The NLAES survey oversampled Black households and the NESARC survey oversampled Black and Hispanic households; this approach generated an increased number of minority respondents for current analyses. Hispanic households were not oversampled for the NLAES, which may have limited our ability to find treatment utilization trends for Hispanics. The analysis of lifetime rates of utilization also provided an adequate sample size to test ethnic group differences in the use of alcohol treatment services, but treatment episodes could have occurred earlier than the 10-year study period.

Results may not be applicable to such excluded populations as institutionalized adults, military personnel living on-base, and youth under 18 years of age. Findings from this general population sample may also not generalize to alcohol dependent persons in clinical 
settings. Trends in treatment utilization from 1991-1992 to 2001-2002 are likely not representative of those observed in other time periods. For example, Mark et al. (2007) reported a growth in private insurance spending from 2001 to 2002, in contrast to the prior 10 years. Treatment utilization rates reported for Hispanics in this study may not apply equally to all Hispanic national groups (i.e., Mexican Americans, Puerto Ricans, Cubans, and South/Central Americans). Differences between Hispanic national groups in rates of drinking and alcohol abuse and dependence (Alegria et al., 2008; Caetano et al., 2008; Caetano et al., 2009) may suggest within ethnic group variability in alcohol services utilization.

Additionally, alcohol treatment measures available in the NLAES and NESARC made it difficult to examine some trends in alcohol services utilization. Survey differences prevented tests of separate trends in inpatient and outpatient treatment utilization. As well, information about whether a treatment service was privately or publically funded was not available. Social pressure and coercion have been recognized as important contributory factors for treatment use (Weisner et al., 1995; Weisner and Schmidt, 2001), including for ethnic minority groups, but these measures were not available for testing. There is a strong connection between the criminal justice system (CJS) and alcohol treatment (Horgan and Merrick, 2001; Weisner and Schmidt, 2001), but alcohol services could not be clearly linked to CJS through survey data.

In conclusion, this study suggests that changes in the organization and financing of alcohol services in the 1990s may have affected rates of treatment use for Whites, Blacks and Hispanics in the general population. Decreases in alcohol services utilization observed from 1991-1992 to 2001-2002 for individuals with AUDs were contrary to substantial increases in treatment utilization during the 1980s. For this study, drinkers also showed increased ER and human services use for alcohol problems. These changes in treatment utilization between survey years appeared to impact all ethnic groups equally. However, the effect of ethnicity on utilization did vary by level of severity. Blacks and Hispanics at higher levels of severity were less likely to ever seek treatment and to use some alcohol treatment services compared to Whites. Blacks and Hispanics also had lower odds for health professional care. Hispanics were less likely to use alcohol or drug programs. Our findings emphasize the need for further research to identify barriers to treatment for these high risk groups, as well as policy solutions for improving reduced trends in treatment utilization across White, Black and Hispanic ethnicities.

\section{Acknowledgments}

We would like to thank Jonali Baruah, PhD, Lori Rodriguez, MPH and Meenal Sawant, MPH for their help in preparing this paper, and Constance Weisner, Dr. P.H. for her constructive suggestions. This work was supported by the U.S. National Institute on Alcohol Abuse and Alcoholism Grant No. R01AA016319.

Source of funding: This work was supported by the U.S. National Institute on Alcohol Abuse and Alcoholism Grant No. R01AA016319.

\section{REFERNCES}

Agency for Healthcare Research and Quality. Addressing Racial and Ethnic Disparities in Health Care, Fact Sheet. Rockville, MD: February. 2000 AHRQ Publication No. 00-PO41

Alegria M, Canino G, Shrout PE, Woo M, Duan N, Vila D, Torres M, Chen CN, Meng XL. Prevalence of mental illness in immigrant and non-immigrant U.S. Latino groups. Am J Psychiatry. 2008; 165:359-369. [PubMed: 18245178]

American Psychiatric Association. Diagnostic and Statistical Manual of Mental Disorders. 3rd ed.. American Psychiatric Association; Washington, DC: 1994. revised 
Arroyo JA, Westerberg VS, Tonigan JS. Comparison of treatment utilization and outcome for Hispanics and non-Hispanic whites. J Stud Alcohol. 1998; 59:286-291. [PubMed: 9598709]

Caetano R, Baruah J, Ramisetty-Mikler S, Ebama MS. Sociodemographic predictors of pattern and volume of alcohol consumption across Hispanics, blacks, and whites: 10-year trends (1992-2002). Alcohol Clin Exp Res. 2010; 34:1782-1792. [PubMed: 20645935]

Caetano R, Ramisetty-Mikler S, Rodriguez LA. The Hispanic Americans Baseline Alcohol Survey (HABLAS): rates and predictors of alcohol abuse and dependence across Hispanic national groups. J Stud Alcohol Drugs. 2008; 69:441-448. [PubMed: 18432387]

Caetano R, Vaeth PA, Ramisetty-Mikler S, Rodriguez LA. The Hispanic americans baseline alcohol survey: alcoholic beverage preference across Hispanic national groups. Alcohol Clin Exp Res. 2009; 33:150-159. [PubMed: 18976346]

Chartier KG, Caetano R. Ethnicity and Health Disparities in Alcohol Research. Alcohol Research and Health. 2010; 33:152-160. [PubMed: 21209793]

Copeland VC. African Americans: Disparities in health care access and utilization. Health Soc Work. 2005; 30:265-270. [PubMed: 16190303]

Coustasse A, Singh KP, Trevino FM. Disparities in access to healthcare: the case of a drug and alcohol abuse detoxification treatment program among minority groups in a Texas hospital. Hosp Top. 2007; 85:27-34. [PubMed: 17405422]

Dawson DA, Grant BF, Stinson FS, Chou PS. Toward the attainment of low-risk drinking goals: A 10year progress report. Alcohol Clin Exp Res. 2004; 28:1371-1378. [PubMed: 15365308]

Dayhoff DA, Urato CJ, Pope GC. Trends in funding and use of alcohol and drug abuse treatment at specialty facilities, 1990-1994. Am J Public Health. 2000; 90:109-111. [PubMed: 10630146]

Etheridge RM, Hubbard RL, Anderson J, Craddock SG, Flynn PM. Treatment structure and program services in the Drug Abuse Treatment Outcome Study (DATOS). Psychology of Addictive Behaviors. 1997; 11:244-260.

Gabel JR, Whitmore H, Pickreign JD, Levit KR, Coffey RM, Vandivort-Warren R. Substance abuse benefits: Still limited after all these years. Health Aff (Millwood). 2007; 26:w474-482. [PubMed: 17556380]

Galanter M, Keller DS, Dermatis H, Egelko S. The impact of managed care on substance abuse treatment: A problem in need of solution. A report of the American Society of Addiction Medicine. Recent Dev Alcohol. 2001; 15:419-436. [PubMed: 11449756]

Grant, BF.; Dawson, DA. Alcohol and drug use, abuse, and dependence: Classification, prevalence, and comorbidity. In: McCrady, BS.; Epstein, EE., editors. Addictions: A Comprehensive Guidebook. Oxford University Press; New York: 1999. p. 9-29.

Grant BF, Dawson DA. Introduction to the National Epidemiologic Survey on Alcohol and Related Conditions. Alcohol Res Health. 2006; 29:74-78.

Grant BF, Dawson DA, Stinson FS, Chou SP, Dufour MC, Pickering RP. The 12-month prevalence and trends in DSM-IV alcohol abuse and dependence: United States, 1991-1992 and 2001-2002. Drug Alcohol Depend. 2004; 74:223-234. [PubMed: 15194200]

Grant BF, Harford TC, Dawson DA, Chou PS, Pickering RP. The Alcohol Use Disorder and Associated Disabilities Interview schedule (AUDADIS): Reliability of alcohol and drug modules in a general population sample. Drug Alcohol Depend. 1995; 39:37-44. [PubMed: 7587973]

Hasin DS, Stinson FS, Ogburn E, Grant BF. Prevalence, correlates, disability, and comorbidity of DSM-IV alcohol abuse and dependence in the United States. Arch Gen Psychiatry. 2007; 64:830 842. [PubMed: 17606817]

Horgan CM, Merrick EL. Financing of substance abuse treatment services. Recent Dev Alcohol. 2001; 15:229-252. [PubMed: 11449744]

Huber JH, Pope GC, Dayhoff DA. National and state spending on specialty alcoholism treatment: 1979 and 1989. Am J Public Health. 1994; 84:1662-1666. [PubMed: 7943492]

Institute of Medicine. A shared destiny: Community effects of uninsurance. The National Academies Press; Washington, DC: 2003.

Institute of Medicine. Hospital-based Emergency Care: At the Breaking Point. The National Academies Press; Washington, DC: 2007. 
Kaskutas LA, Weisner C, Caetano R. Predictors of help seeking among a longitudinal sample of the general population, 1984-1992. J Stud Alcohol. 1997; 58:155-161. [PubMed: 9065893]

Kaskutas LA, Weisner C, Lee M, Humphreys K. Alcoholics anonymous affiliation at treatment intake among white and black Americans. J Stud Alcohol. 1999; 60:810-816. [PubMed: 10606493]

Magura S, Horgan CM, Mertens JR, Shepard DS. Effects of managed care on alcohol and other drug (AOD) treatment. Alcohol Clin Exp Res. 2002; 26:416-422. [PubMed: 11923597]

Mark TL, Coffey RM. The decline in receipt of substance abuse treatment by the privately insured, 1992-2001. Health Aff (Millwood). 2004; 23:157-162. [PubMed: 15537594]

Mark TL, Coffey RM, Vandivort-Warren R, Harwood HJ, King EC. U.S. spending for mental health and substance abuse treatment, 1991-2001. Health Aff (Millwood) Suppl Web Exclusives. 2005:w5-133-w135-142.

Mark TL, Levit KR, Vandivort-Warren R, Coffey RM, Buck JA. Trends in spending for substance abuse treatment, 1986-2003. Health Aff (Millwood). 2007; 26:1118-1128. [PubMed: 17630455]

Mulia N, Ye Y, Greenfield TK, Zemore SE. Disparities in alcohol-related problems among white, black, and Hispanic Americans. Alcohol Clin Exp Res. 2009; 33:654-662. [PubMed: 19183131]

National Institute on Alcohol Abuse and Alcoholism. U.S. Alcohol Epidemiologic Data Reference Manual. Vol. 6. National Institute of Health; Bethesda, MD: 1998. Drinking in the United States: Main findings from the 1992 National Longitudinal Alcohol Epidemiologic Survey (NLAES).

National Institute on Alcohol Abuse and Alcoholism. U.S. Alcohol Epidemiologic Data Reference Manual. Vol. 8. National Institute of Health; Bethesda, MD: 2006. Alcohol use and alcohol use disorders in the United States: Main findings from the 2001-2002 National Epidemiologic Survey on Alcohol and Related Conditions (NESARC).

National Institute on Alcohol Abuse and Alcoholism. [Accessed July 14, 2010]. Available at: http://pubs.niaaa.nih.gov/publications/datasys.htm

Owen PL, Slaymaker V, Tonigan JS, McCrady BS, Epstein EE, Kaskutas LA, Humphreys K, Miller WR. Participation in alcoholics anonymous: intended and unintended change mechanisms. Alcohol Clin Exp Res. 2003; 27:524-532. [PubMed: 12658120]

Research Triangle Institute. SUDAAN. 10.0 ed.. RTI International; Research Triangle Park, NC: 2008.

Schmidt L, Weisner C. Developments in alcoholism treatment. Recent Dev Alcohol. 1993; 11:369_ 396. [PubMed: 8234931]

Schmidt L, Ye Y, Greenfield TK, Bond J. Ethnic disparities in clinical severity and services for alcohol problems: Results from the National Alcohol Survey. Alcohol Clin Exp Res. 2007; 31:4856. [PubMed: 17207101]

Steenrod S, Brisson A, McCarty D, Hodgkin D. Effects of managed care on programs and practices for the treatment of alcohol and drug dependence. Recent Dev Alcohol. 2001; 15:51-71. [PubMed: 11449757]

Substance Abuse and Mental Health Services Administration. [Accessed May 19, 2010]. 2005 Available at: http://www.oas.samhsa.gov/nhsda/2k2nsduh/Sect5peTabs82to83.pdf

Tonigan JS, Miller WR, Juarez P, Villanueva M. Utilization of AA by Hispanic and non-Hispanic white clients receiving outpatient alcohol treatment. J Stud Alcohol. 2002; 63:215-218. [PubMed: 12033698]

Weisner C, Greenfield T, Room R. Trends in the treatment of alcohol problems in the US general population, 1979 through 1990. Am J Public Health. 1995; 85:55-60. [PubMed: 7832262]

Weisner C, Matzger H, Tam T, Schmidt L. Who goes to alcohol and drug treatment? Understanding utilization within the context of insurance. J Stud Alcohol. 2002; 63:673-682. [PubMed: 12529067]

Weisner C, McCarty D, Schmidt L. New directions in alcohol and drug treatment under managed care. Am J Manag Care. 1999; 5 Spec No:SP57-69.

Weisner C, Schmidt LA. Rethinking access to alcohol treatment. Recent Dev Alcohol. 2001; 15:107136. [PubMed: 11449738]

Zemore SE, Mulia N, Yu Y, Borges G, Greenfield TK. Gender, acculturation, and other barriers to alcohol treatment utilization among Latinos in three National Alcohol Surveys. J Subst Abuse Treat. 2009; 36:446-456. [PubMed: 19004599] 


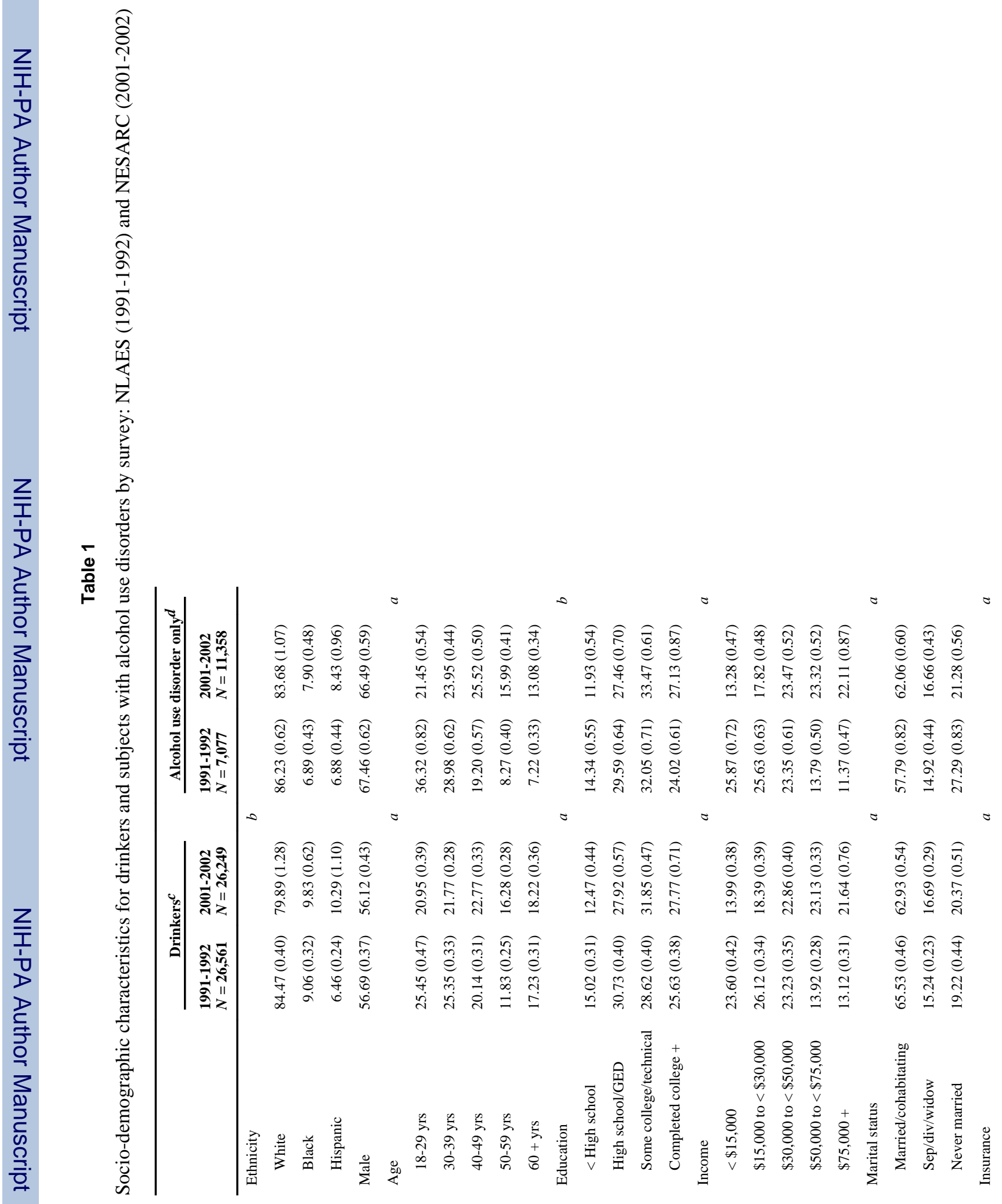




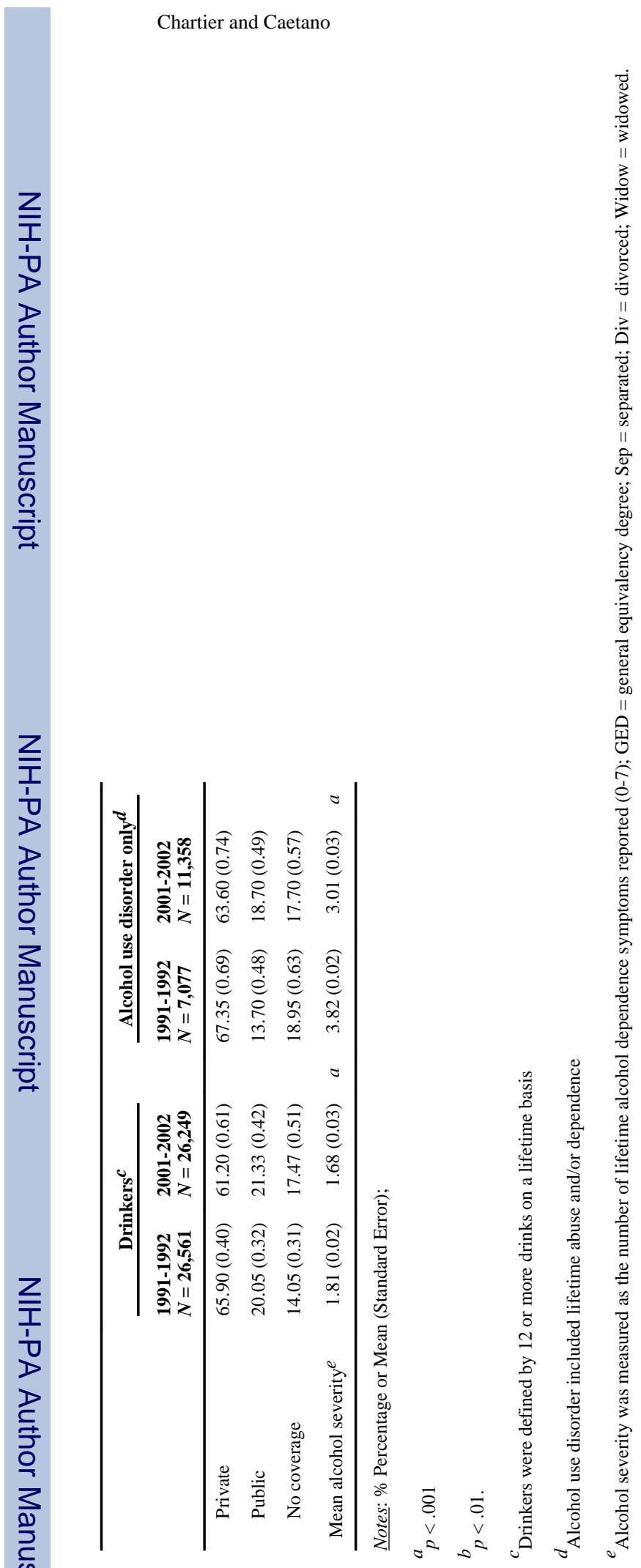

Alcohol Clin Exp Res. Author manuscript; available in PMC 2012 August 1. 


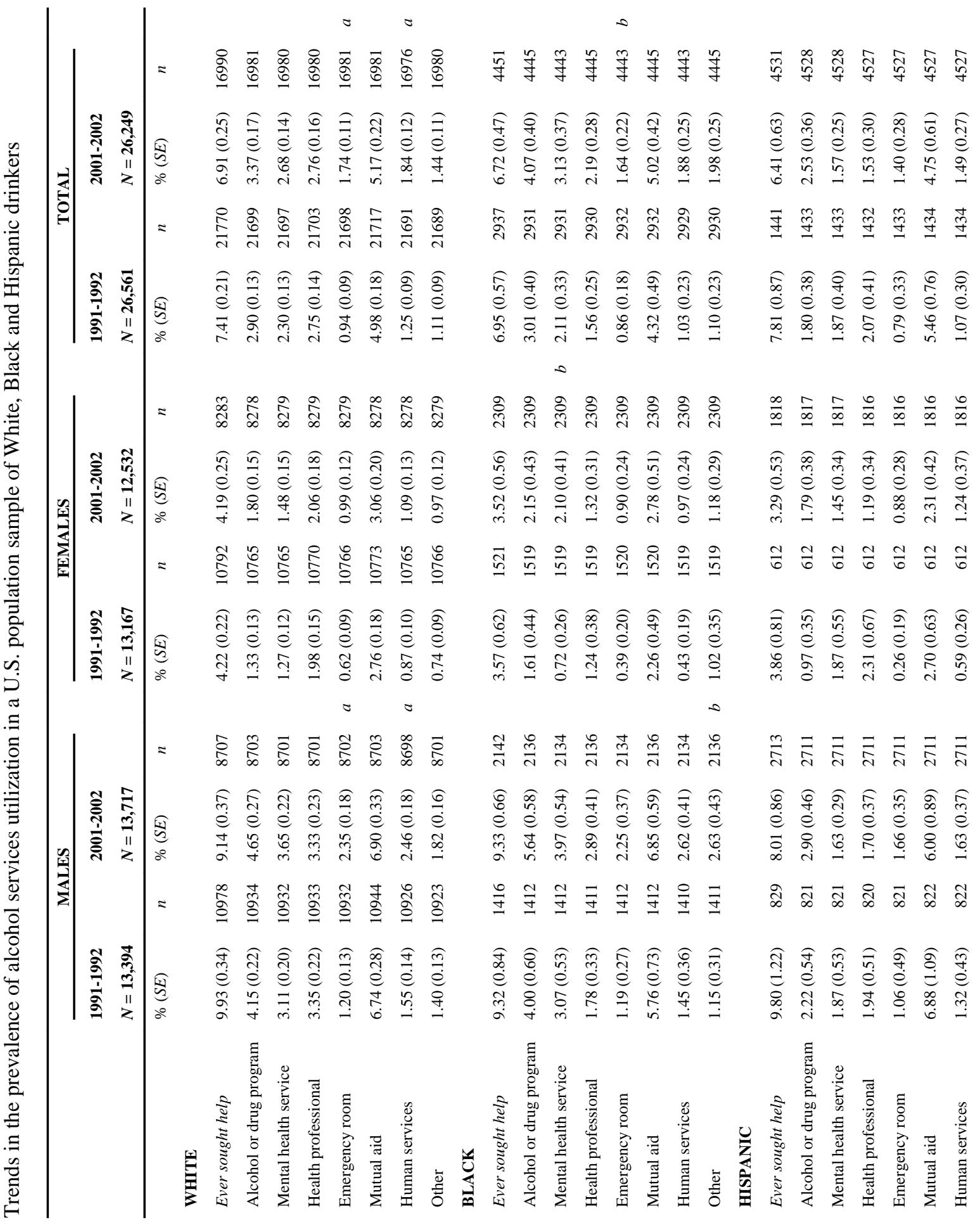




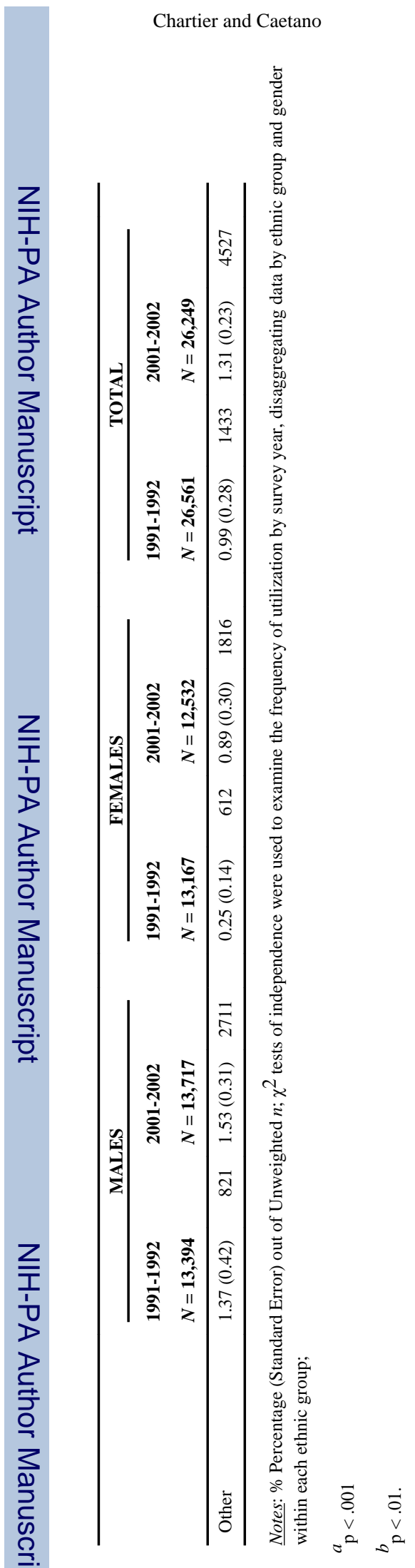

Alcohol Clin Exp Res. Author manuscript; available in PMC 2012 August 1. 


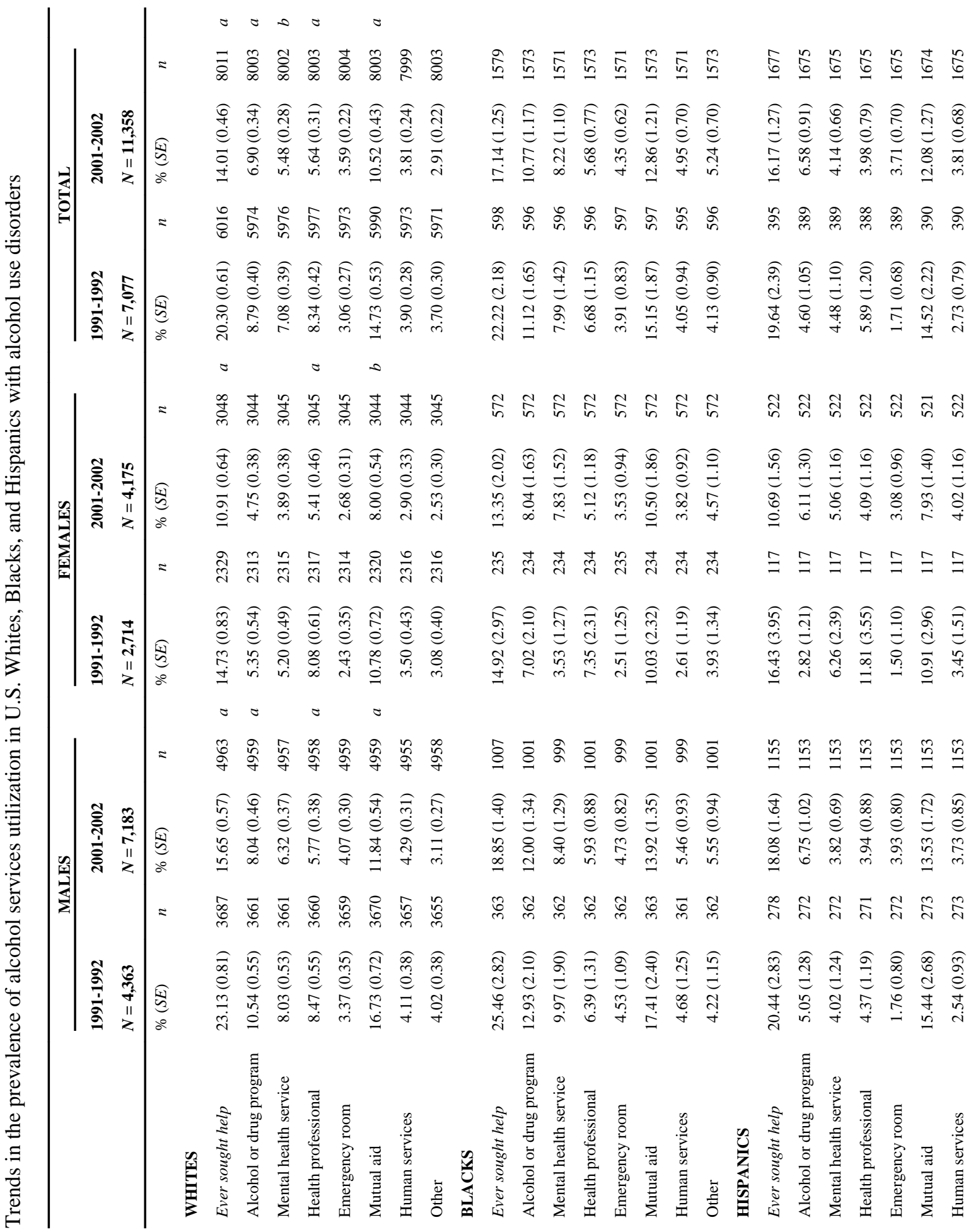




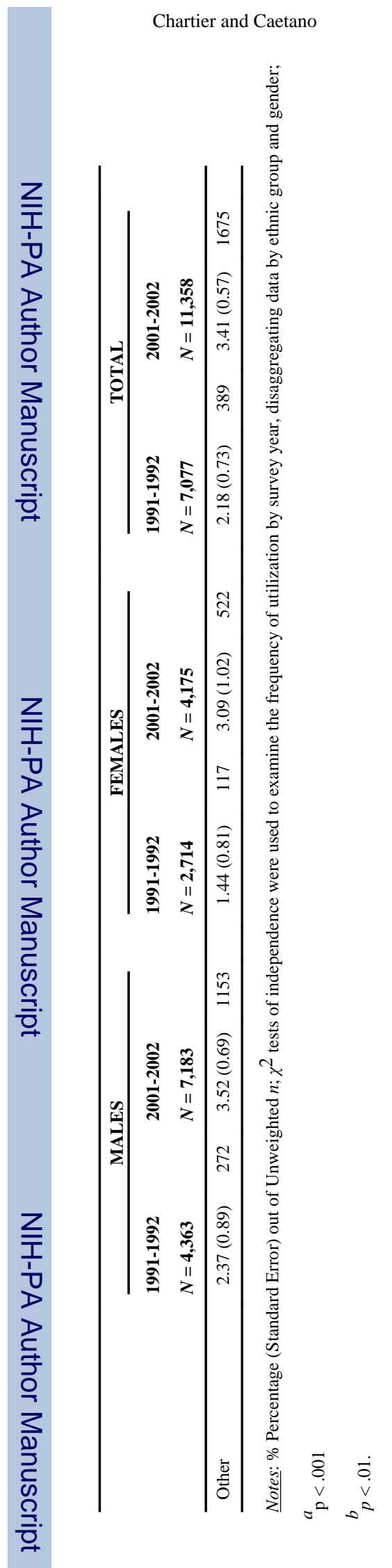

Alcohol Clin Exp Res. Author manuscript; available in PMC 2012 August 1. 


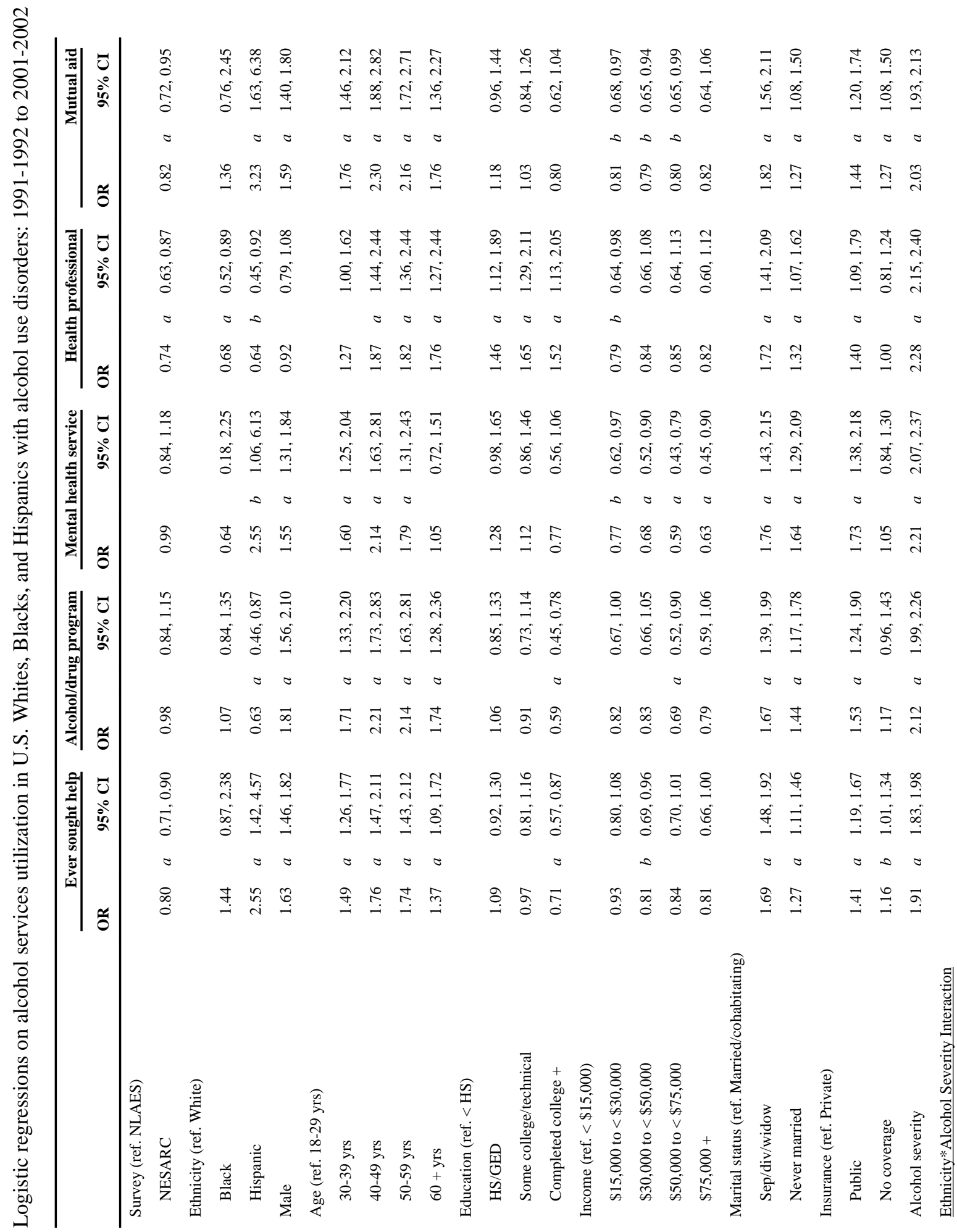




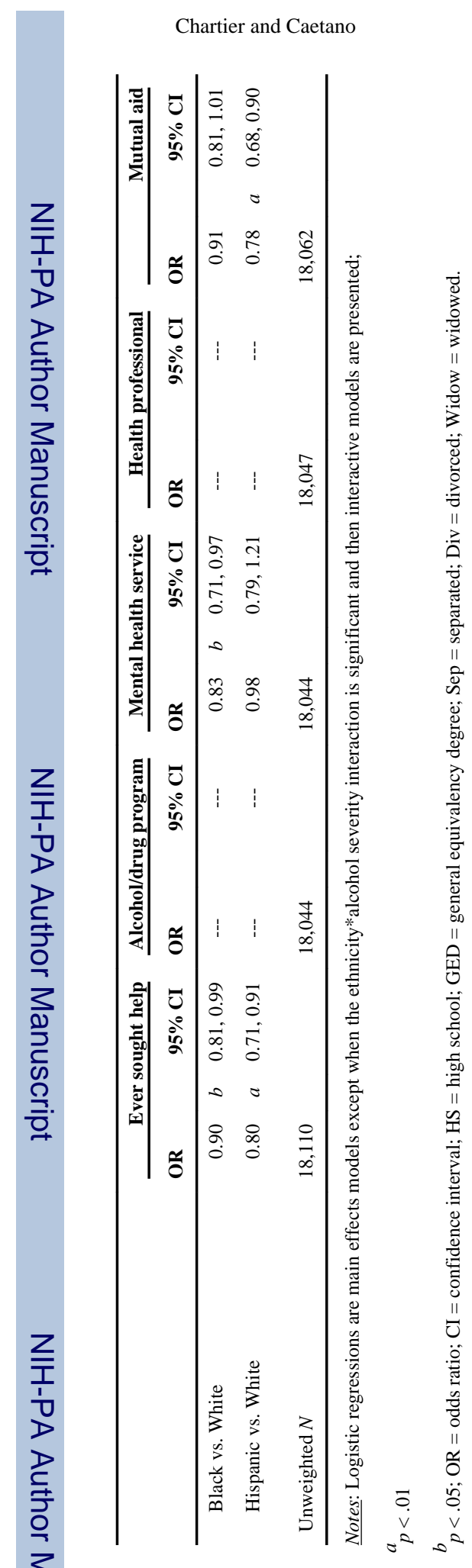

Alcohol Clin Exp Res. Author manuscript; available in PMC 2012 August 1. 


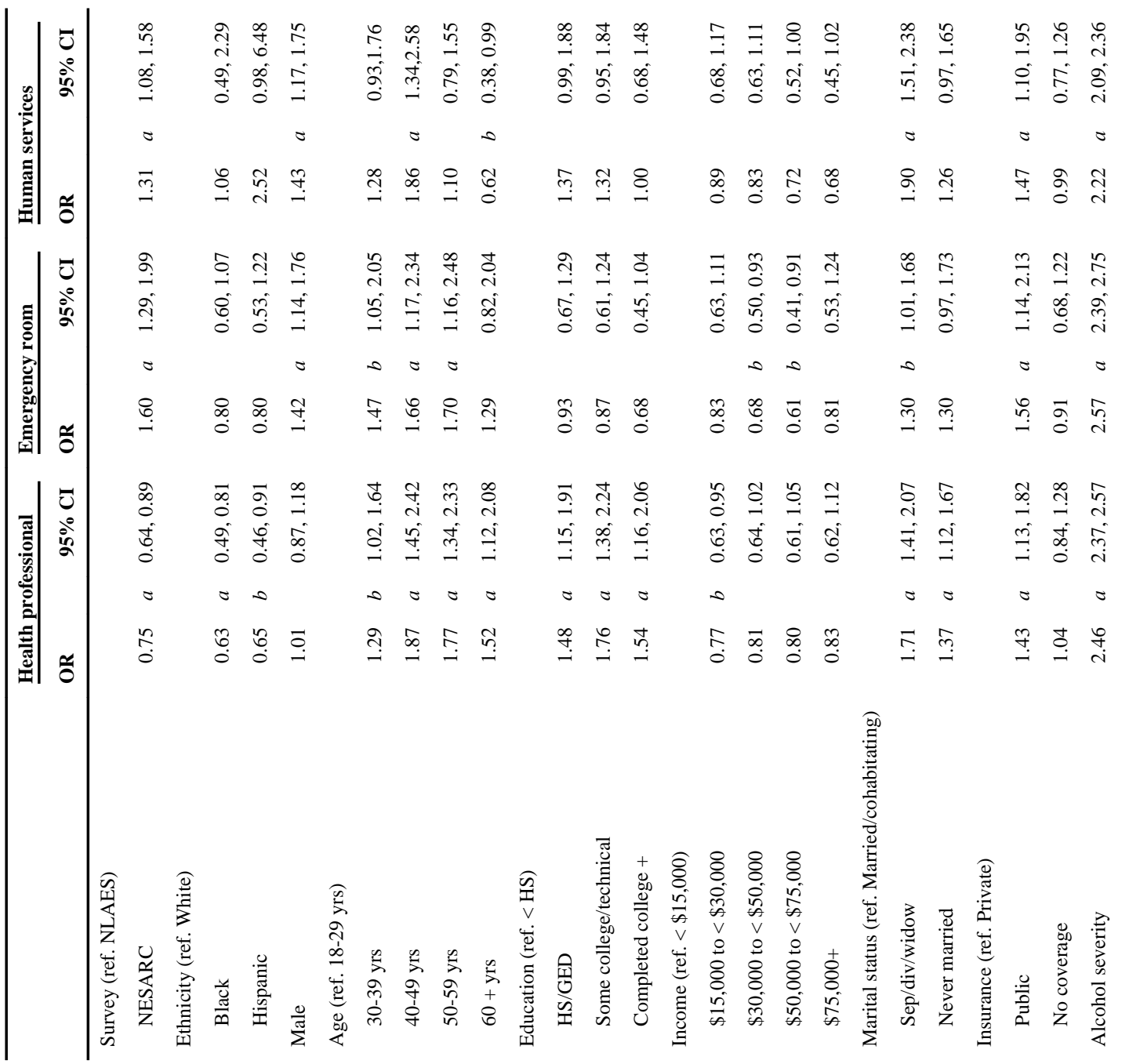




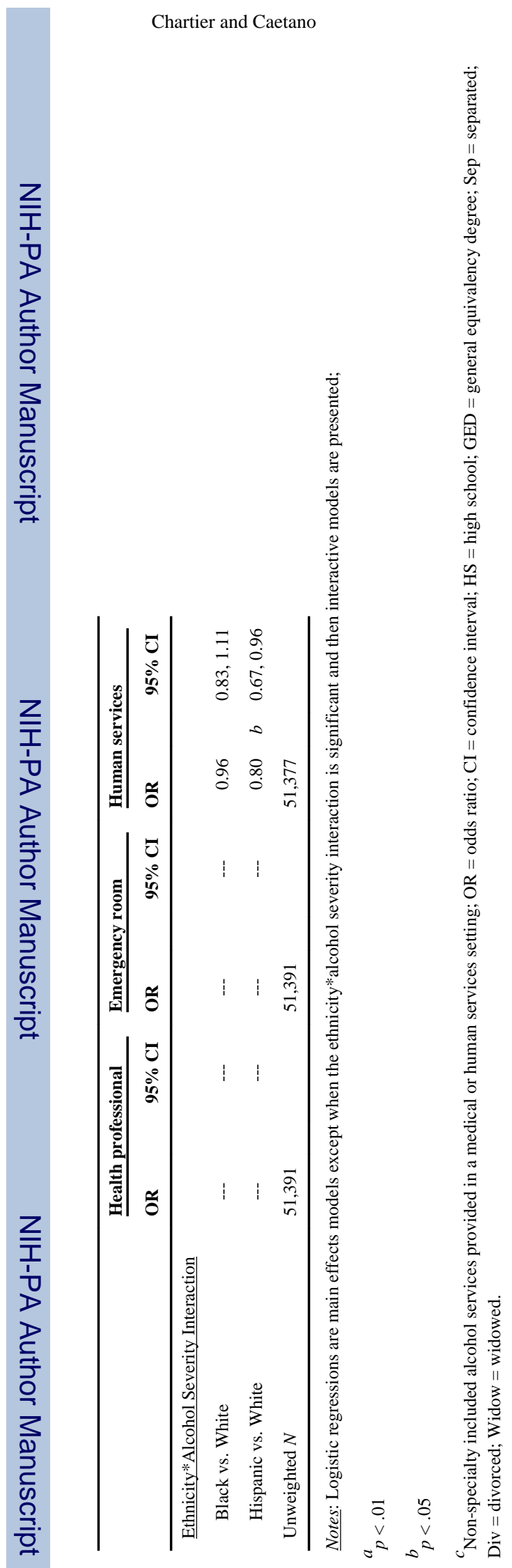

Alcohol Clin Exp Res. Author manuscript; available in PMC 2012 August 1. 